\title{
Performance, Emission and Combustion Characteristics of VCR CRDI Diesel Engine Fuelled with n-Butanol Blends
}

\section{P. Tamilselvan and G. Gangeya Srinivasu*}

School of Mechanical and Building Sciences, VIT University, Chennai -600127, India. *Email: ggsvas@gmail.com

\begin{abstract}
This research work indicates the analysis conducted to investigate the performance, exhaust emission and combustion characteristics of a VCR diesel engine fuelled with nbutanol blends at a rated speed of $1500 \mathrm{rpm}$ with 300 bar injection pressure at compression ratios of 16,18 and 20 . The test fuel was prepared by adding n-butanol $10 \%$ (NB10) and 20\% (NB20) to diesel by volume. The combustion characteristics investigated were; rise in-cylinder pressures, net heat release rate, cumulative heat release rate and mass fraction of fuel burned at all loads using three compression ratios. The emission and performance study also conducted. The higher heat release rates, increased cylinder pressures were observed for both the blends compared to diesel. Increased brake thermal efficiency observed at higher compression ratio for NB20 blend. It had also been observed that the emissions of $\mathrm{CO}_{2}, \mathrm{HC}$ and $\mathrm{NOx}$ were increased for both the blends, while $\mathrm{CO}$ emissions decreased in trend with an increase in compression ratio and blend strength.
\end{abstract}

Keywords: Thermal efficiency; compression ratio; combustion; heat release rate; ignition delay.

\section{NOMENCLATURE}

$\begin{array}{ll}\text { NB10 } & 10 \% \text { n-butanol, } 90 \% \text { diesel } \\ \text { NB20 } & \text { 20\% n-butanol, 80\% diesel } \\ \text { VCR } & \text { variable compression ratio } \\ \text { CRDI } & \text { common rail direct injection } \\ \text { CHR } & \text { cumulative heat release } \\ \text { CR16 } & \text { compression ratio 16 } \\ \text { CR18 } & \text { compression ratio 18 } \\ \text { CR20 } & \text { compression ratio 20 } \\ \text { BSFC } & \text { brake specific fuel consumption } \\ \text { BTE } & \text { brake thermal efficiency } \\ \text { CO } 2 & \text { carbon dioxide } \\ \text { NOx } & \text { nitrogen oxides } \\ \text { HC } & \text { hydrocarbons } \\ \text { ppm } & \text { parts per million } \\ \text { BTDC } & \text { before top dead centre } \\ \text { MFB } & \text { mass fraction burned } \\ \text { NHR } & \text { net heat release rates } \\ \text { CO } & \text { carbon monoxide }\end{array}$




\section{INTRODUCTION}

Since the utilisation of diesel engines and their increased occupancy in all aspects, comprehensive research and experimental studies have been going on to reduce their exhausting gaseous emissions. The primary concern is meant for reducing the conventional diesel fuel usage to minimise air pollution and to boost efforts to reduce greenhouse gases accumulation in the environment. There is also need for curb down the depletion of fossil fuels by utilising the alternate fuel usage [1] with increased combustion phenomenon technologies like HCCI, PCCI, RCCI and other technological improvements in engine design and operating parameters.

The alternative fuel must be biodegradable and non-toxic with properties near to diesel and it must be a substitute to diesel with little or no engine modifications. In this concern number of researches, processes are going on by various researchers and combustion specialists by using various alternative fuels. This research work primarily deals with the utilisation of alcohol-based fuels in diesel engines because they are considered as bio-oxygenated compounds with low viscosity, high volatility and miscibility with diesel. In alcoholic based fuels, butanol is the most suitable substitute for diesel engines compared to ethanol because of its maximum energy density, less corrosive nature and less prone to contamination in the presence of water content [2]. This fuel is also considered a clean alternative source for fossil fuels to reduce greenhouse emissions. Several research works were carried by researchers to study n-butanol/diesel blend combinations on engine performance and to regulate emissions. The novelty of this analysis is to study the performance, emission and combustion phenomenon at various compression ratios using blends of n-butanol at different loads.

Javed Rezaei et al. [3] concluded Butanol and ethanol are promising alternative substitutes for conventional fuels when utilised in advanced combustion mode like HCCI. Senthur Prabhu et al. [4] used the blend $20 \%$ preheated palm oil with diesel with additives n-butanol $20 \%$ by volume and BHT 2000ppm. The results are shown with improved BSFC with BTE and reduced CO emissions compared to diesel. Alpaslan Atman et al. [5] used blends of canola-hazelnut-cottonseed oil and sunflower-corn-soybean oil separately with diesel $70 \%$ and n-butanol $10 \%$ by volume. The results obtained were, decreased brake power with BTE and improved BSFC compared to diesel and; $\mathrm{CO}_{2}, \mathrm{HC}$ emissions decrease with increased $\mathrm{CO}$ emissions. The effect of pilot injection timing and pilot injection mass on high-speed diesel engine was studied by Haozhong Huang et al. [6] using n-butanol (20\% and $30 \%$ by volume) and diesel blends. The results revealed that the peak value of NHR decreased with advancing injection timing for pre-injection fuel but increased slightly for main injection fuel. NOx and soot emissions were reduced. And also by increasing the pilot injection fuel mass peak value of NHR improved. Ashish Nayyar et al. [7] utilised n-butanol blends in small VCR diesel engine, for $20 \%$ of the nbutanol blend with diesel shown increased BTE with decreased smoke and NOx emissions at higher compression ratios. Anil Bhaurao Wakal et al. [8] used different fuel injection strategies for diesel, n-butanol blends. By retarding the start of injection $(9,7$ to $4^{\circ}$ BTDC) the in-cylinder pressure, peak HRR and NOx emissions were decreased. The start of injection at $4^{\circ}$ BTDC led $30-45 \%$ decreased NOx levels.

Polyoxymethylene di-ethyl ethers considered as an excellent biofuel with nbutanol/diesel blends in diesel engines [9]. Results indicate that by adding PODE $_{3-4}$ to the blend of n-butanol with diesel can improve the thermal efficiency and combustion efficiency with an increment in BSFC. A decrease in trend was observed in the emissions of soot, $\mathrm{CO}$, and THC while the increase in NOx formation. The emissions of n-butanol 
blend with diesel were studied on CRDI turbocharged engine by Byungchul Choi et al.[10]. The results revealed that increased NOx emissions for n-butanol blends compared to neat diesel and for $20 \%$ n-butanol blend THC and $\mathrm{CO}$ emissions increased significantly, and for higher blend ratio ( $>20 \%$ ) HCHO (formaldehyde) increased at low loading conditions. Zehra Sahin et al. [11] used blending and fumigation technique for nbutanol introduction into diesel engine. The smoke decreased significantly by applying the above two methods. The above literature is confirming that alcoholic based fuels line n-butanol could be used in diesel engines with little or no engine modifications.

NO emissions were improved by using butanol, biodiesel and diesel blend combinations in diesel engines. The increase or decrease of NOx emission depends on the particular operating parameters. In some experiments by using exhaust gas recirculation NOx emissions were controlled [12]. The RCCI concept was used by Mostafa Mohebbi et al. [13] by directly injecting butanol-diesel blends into the combustion chamber and gasoline into the intake port. The results indicated that the start of combustion delayed by n-butanol addition, and it was compensated by adjusting the injection timing. The $\mathrm{CO}$ emissions were reduced, but $\mathrm{HC}$ emissions were increased because of $n$-butanol high latent heat of vaporisation, and it is controlled by exhaust gas recirculation.

From the above literature survey, it has been concluded that n-butanol could be used in conventional diesel engines with little or no engine modifications. Table 1 indicates the properties of n-butanol compared to other alcohol-based fuels and diesel. The objective of this experimental analysis is to research combustion, emission and performance parameters of n-butanol blends at various compression ratios. The primary objective of choosing n-butanol as test fuel is because of its oxygen percentage to improve its combustion efficiency [14], low-pressure evaporation, its better heating value and cetane number and also its availability as a renewable fuel.

\section{MATERIALS AND METHOD}

Biodiesel blends were prepared and tested according to the standard of ASTM D6751 and EN 14214 using biodiesel with a density of less than $859 \mathrm{~kg} / \mathrm{m}^{3}$, the kinematic viscosity of less than $4.1 \mathrm{cSt}$ and maintaining the calorific value for a blend higher than $35 \mathrm{MJ} / \mathrm{kg}$.

The test fuel n-butanol was mixed with diesel in volume ratios of $10 \%$ and $20 \%$ and named as NB10 and NB20 blends. Table 1 summarises the properties of the n-butanol and diesel. The diesel and test fuel blends were used on VCR engine with compression ratios of 16, 18 and 20 form no load to full load conditions.

The experimental setup is shown in Figure 1, and its technical specifications are shown in Table 2. Experimental investigations were carried out by using CRDI VCR diesel engine with eddy current dynamometer at a rated rpm of 1500 with an injection pressure of 300 bar and with an injection timing of $23^{\circ}$ BTDC. The VCR engine was provided with AVL DI GAS $444 \mathrm{~N}$ five gas analyser and AVL 437C smoke meter. The setup enables the study of CRDI VCR engine performance with programmable ECU at different compression ratios.

Various necessary instruments were used along with experimental setup to measure the crank angle, combustion rate, in-cylinder pressure and temperatures and fuel flow rates. The signals from all the measuring instruments were connected to a computer through a data acquisition system. Series of the experiment trial were conducted on the test engine with test fuels, and the average value of all trail readings from no load to full load conditions was taken. After allowing the engine to get stabilised with applied loads 
during each experimental trial, the emission, combustion and performance details were recorded.

Table 1. The basic test fuel properties.

\begin{tabular}{lcccc}
\hline Details & Diesel & n-butanol & NB10 & NB20 \\
\hline Cetane number & 50 & 17 & 46.53 & 43.4 \\
Stochiometric A/F ratio & 14.95 & 11.17 & 14.46 & 14.2 \\
$\mathrm{O}_{2}(\mathrm{wt} \%)$ & 0 & 21.58 & 2.158 & 4.32 \\
Carbon wt \% & 86.12 & 64.82 & 83.34 & 81.86 \\
Hydrogen wt \% & 13.87 & 13.60 & 13.84 & 13.82 \\
Lower heating value $(\mathrm{kJ} / \mathrm{kg})$ & 43400 & 33100 & 42370 & 41340 \\
Kinematic viscosity $(\mathrm{cSt})$ at $40^{\circ} \mathrm{C}$ & 3.9 & 2.63 & 3.773 & 3.646 \\
Density $\left(\mathrm{kg} / \mathrm{m}^{3}\right)$ at $15^{\circ} \mathrm{C}$ & 838 & 810 & 835.2 & 832.4 \\
Molecular weight $(\mathrm{g} / \mathrm{mol})$ & 198.4 & 74.11 & 185.9 & 173.54 \\
\hline
\end{tabular}

Table 2. Test engine specifications.

\begin{tabular}{lc}
\hline Parameters & Specification \\
\hline Type of engine & Kirloskar, CRDI, four-stroke, single-cylinder, \\
naturally aspirated diesel engine \\
Power & $3.5 \mathrm{~kW}$ at $1500 \mathrm{rpm}$ \\
Bore $\times$ stroke & $87.5 \mathrm{~mm} \mathrm{x} 110 \mathrm{~mm}$ \\
Compression ratio & $17.5(\mathrm{VCR} 12$ to 22$)$ \\
Injection pressure & $300 \mathrm{bar}$ \\
Injection timing & $23^{\circ} \mathrm{BTDC}$ \\
Swept volume & $661.45(\mathrm{cc})$ \\
Dynamometer & Eddy current type \\
\hline
\end{tabular}

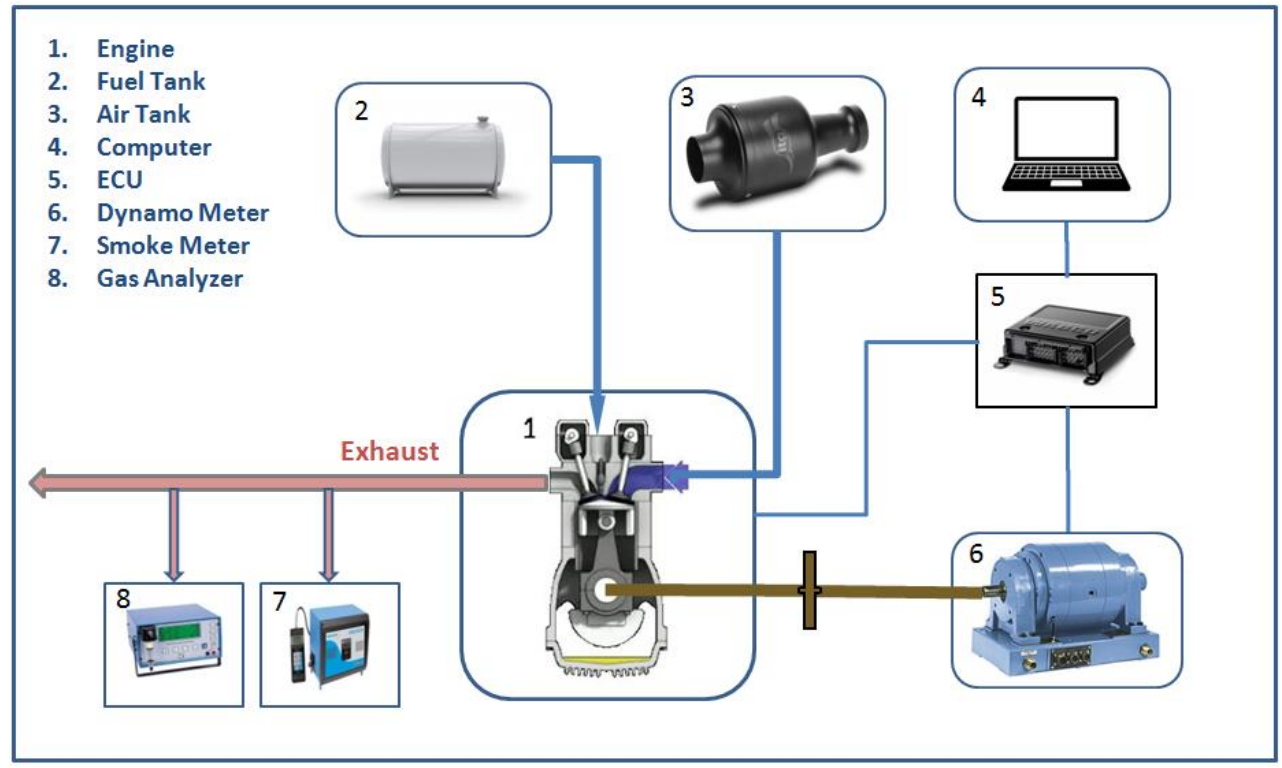

Figure 1. Schematic diagram of the experimental setup. 


\section{RESULTS AND DISCUSSION}

\section{Engine Performance Analysis}

\section{Brake thermal efficiency}

The brake thermal efficiency is described as the ratio of the amount of heat converted to the brake power to the total heat supplied or inverse product of brake specific fuel consumption and calorific value of the fuel [5]. The variation of BTE with respect to load is shown in Figure 2(a) and 2(b).

The BTEs observed at CR16 are 34.65\%, 32.77\% and 34.79\% and at CR20 they were observed as $27.74 \%, 32.75 \%$ and $32.7 \%$ for diesel, NB10 and NB20 respectively at full load conditions. The reduction in BTE was observed as $19.94 \%$ for diesel with an increase of compression ratio from 16 to 20, which was negligible for other blends.

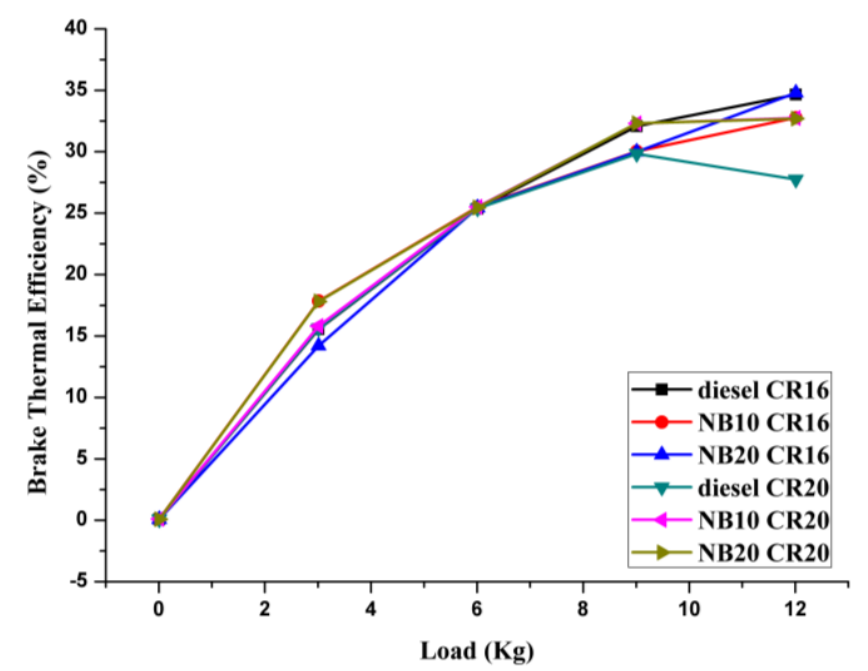

(a)



(b)

Figure 2. Variation of brake thermal efficiency with load at (a) CR16, CR20 and; (b) CR18. 
There is no considerable variation in BTE at CR16 for both the blends compared to diesel. Reduction in BTEs was observed for diesel and both the blends because of increased BSFC with an increase in compression ratios to 18 and 20. Increase in BSFC was due to higher operating temperatures, which in turn led to increased friction powers. There is only a small decrease in BTE observed for both the blends compared to diesel because of their oxygen percentages and better evaporation rates [15]. The decreased cetane number of the blends can also consider as a factor for reduction in BTE [16] because cetane number can influence the combustion efficiency. The improved compression ratios were further decreased BTEs for both the blends and diesel.

\section{Brake specific fuel consumption}

It is defined as the amount of fuel consumed per unit brake power output, or it is the effectiveness to convert the chemical energy of the fuel into useful work, and it depends on fuel properties like viscosity, oxygen content, density, cetane number and heating value. Figure 3(a) and 3(b) show the BSFC values for diesel and n-butanol blends with an increase in loads. Considerable decrease in BSFC observed for both the blends compared to diesel at all compression ratios. From the graph, it is observed that there was a comparable result with diesel for BSFC with an increase in load due to complete combustion with elevated operating temperatures for both the blends.

Figure 3(b) indicates the variation of BSFCs at CR18 with loads. For diesel it was observed as $0.54 \mathrm{~kg} / \mathrm{kW}$-hr, $0.33 \mathrm{~kg} / \mathrm{kW}-\mathrm{hr}, 0.27 \mathrm{~kg} / \mathrm{kW}$-hr and $0.276 \mathrm{~kg} / \mathrm{kW}-\mathrm{hr}$ at $3 \mathrm{~kg}$, $6 \mathrm{~kg}, 9 \mathrm{~kg}$ and $12 \mathrm{~kg}$ loads respectively. Graph for NB 10 shows $0.5 \mathrm{~kg} / \mathrm{kW}-\mathrm{hr}, 0.33$ $\mathrm{kg} / \mathrm{kW}-\mathrm{hr}, 0.27 \mathrm{~kg} / \mathrm{kW}-\mathrm{hr}$ and $0.26 \mathrm{~kg} / \mathrm{kW}$-hr and for NB20 blend $0.55 \mathrm{~kg} / \mathrm{kW}-\mathrm{hr}, 0.33$ $\mathrm{kg} / \mathrm{kW}-\mathrm{hr}, 0.27 \mathrm{~kg} / \mathrm{kW}-\mathrm{hr}$ and $0.25 \mathrm{~kg} / \mathrm{kW}$-hr respectively for $3 \mathrm{~kg}, 6 \mathrm{~kg}, 9 \mathrm{~kg}$ and $12 \mathrm{~kg}$ loads. BSFC decrease in trend from low load to part-load conditions because of reduced heat loss at higher loads, which can influence the evaporation rate of the fuel. The decrease in BSFC with an increase in load may also due to variation of mixture strength from leaner to stoichiometric ratio [15]. The similar trend was observed for both NB10 and NB20 blends because of improved fuel combustion phenomenon with increased loads. The BSFC was slightly increased at full load condition for diesel due to increased radiation losses and decreased mechanical efficiency. BSFC almost same for both nbutanol blends compared to diesel due to its higher evaporation rates even at lower pressures caused thorough mixing with air. This means brake specific energy consumption (BSEC) decreased compared to diesel. BSEC is a product of BSFC and calorific value of particular fuel. It indicates the energy consumed for unit brake power output per hour [17].

BSFCs obtained for CR16 at full load conditions were $0.24 \mathrm{~kg} / \mathrm{kW}-\mathrm{hr}, 0.26$ $\mathrm{kg} / \mathrm{kW}$-hr and $0.24 \mathrm{~kg} / \mathrm{kW}$-hr and at CR20 observed as $0.31 \mathrm{~kg} / \mathrm{kW}-\mathrm{hr}, 0.26 \mathrm{~kg} / \mathrm{kW}-\mathrm{hr}$ and $0.26 \mathrm{~kg} / \mathrm{kW}$-hr for diesel, NB10 and NB20 respectively. The increase in BSFC was observed for NB10 at lower compression ratio compared to diesel, and it was rectified soon after an increase of compression ratio because of increased operating temperatures that allowed complete combustion. 


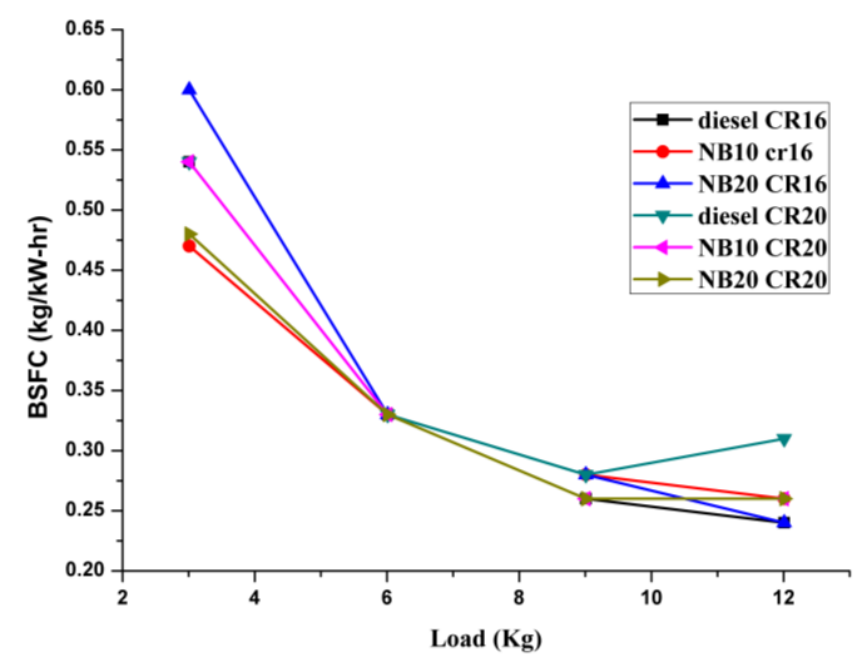

(a)

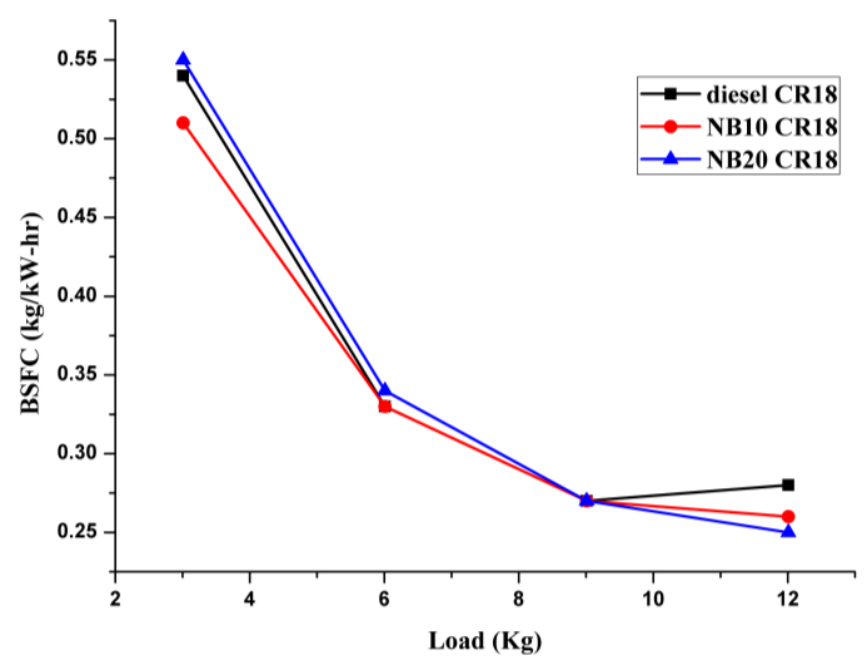

(b)

Figure 3. Variation of BSFC with load at (a) CR16, CR20 and; (b) CR18.

\section{Emission Analysis}

\section{Analysis of carbon monoxide}

The main reason for $\mathrm{CO}$ emission is due to decreased oxygen percentage, rich mixture and incomplete combustion [5]. Heterogeneous mixture formation decreased reactive rates, or slow flame propagation are also considered as a collective reason for the formation of these emissions. It is observed that $\mathrm{CO}$ emission was more for diesel at all compression ratios compared to n-butanol blends from Figures 4(a) and 4(b). They were in a decrease trend with an increase in blend strength because of improved oxygen percentages and evaporation rates. Another factor also influencing $\mathrm{CO}$ emissions is carbon content. The carbon content in n-butanol is $\sim 64.9 \%$, and for diesel, it is $\sim 86.4 \%$ on a mass basis, which also can lead a lower energy level for n-butanol based fuel and lower CO emission [2].

It also has been observed that $\mathrm{CO}$ emissions were improved with the increase of compression ratio. This may be due to decreased penetration of injected fuel droplets at higher compression ratios with the same injection pressures led to heterogeneous mixture 
formation. At CR16 and full load conditions the CO emissions were $0.375 \%, 0.40 \%$ and $0.175 \%$ for diesel, NB10 and NB20 respectively and at CR20 they were observed as $0.777 \%, 0.645 \%$ and $0.571 \%$.

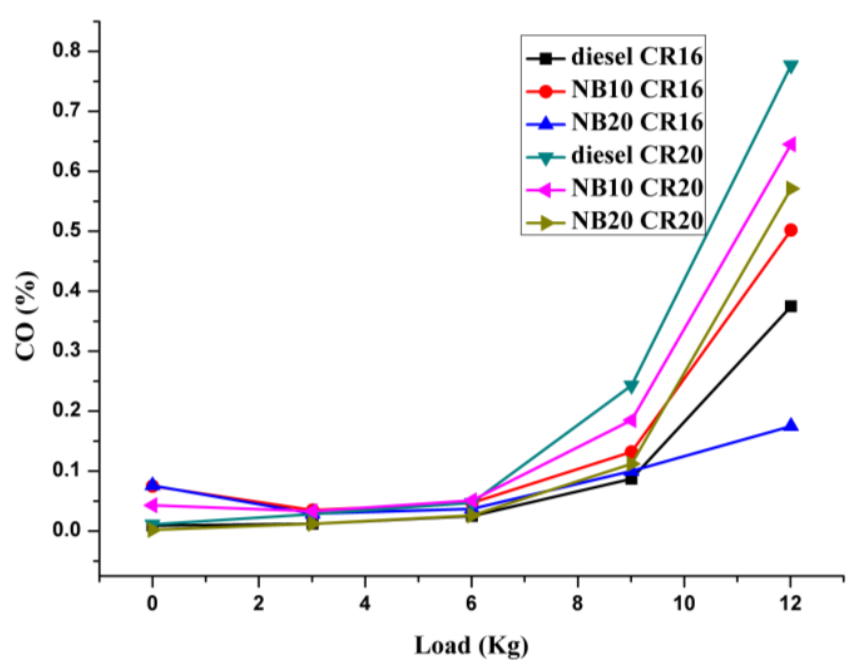

(a)

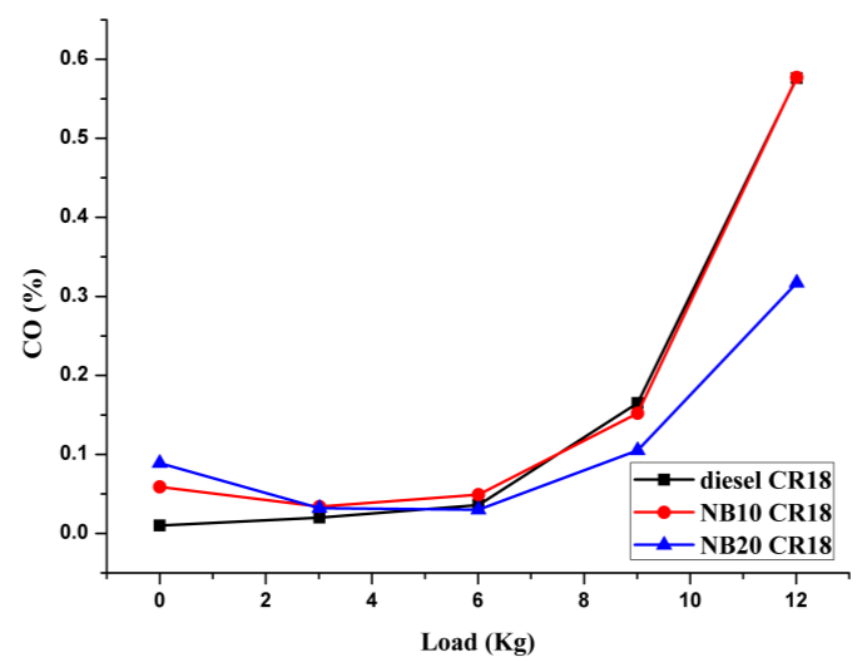

(b)

Figure 4. Variation of carbon monoxide emission with load at (a) CR16 and CR20 and;

(b) CR18

\section{Analysis of carbon dioxide}

The $\mathrm{CO}_{2}$ emission is an indication of increased reaction rates with improved oxygen percentages or conversion of $\mathrm{CO}$ into $\mathrm{CO}_{2}$ after complete combustion of fuel at elevated temperatures[18]. It is also considered as a chemical residue after the combustion of hydrocarbon-based fuels. Homogeneous mixture formation and improved flame propagation rates are also considered as another factor for improved $\mathrm{CO}_{2}$ emissions.

The variation of $\mathrm{CO}_{2}$ with respect to load is shown in Figures 5(a) and 5(b). There is no considerable change in $\mathrm{CO}_{2}$ emissions at $\mathrm{CR} 16$, but as the compression ratio increased to 18 and 20, an increase in the trend of $\mathrm{CO}_{2}$ emissions was observed for both blends compared to diesel. The $\mathrm{CO}_{2}$ emissions at full load conditions for CR20 were 
$7.63 \%, 8.54 \%$ and $7.9 \%$ for diesel, NB10 and NB20 respectively. The improved $\mathrm{CO}_{2}$ emissions for both n-butanol blends were because of their $\mathrm{O}_{2}$ percentages and increased evaporation rates.

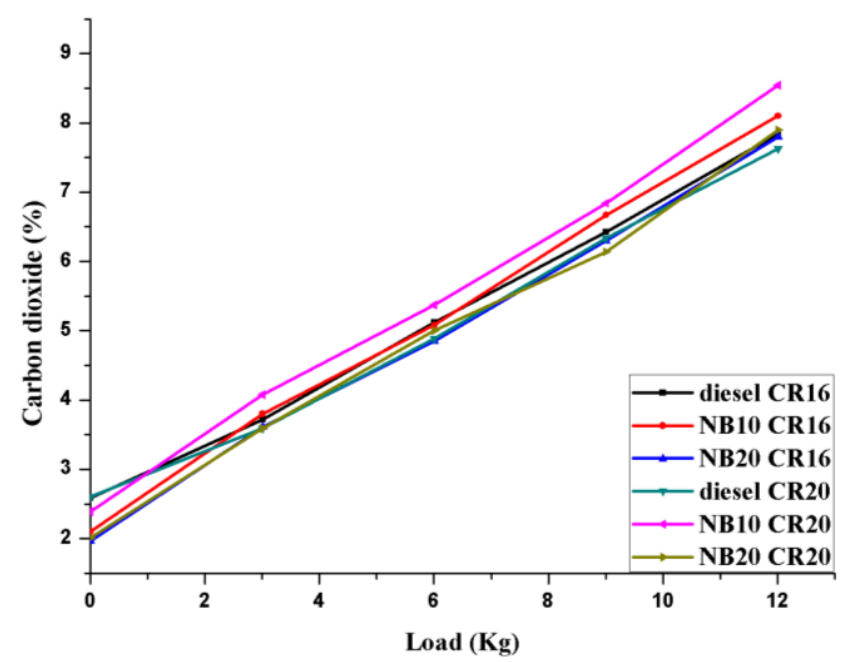

(a)

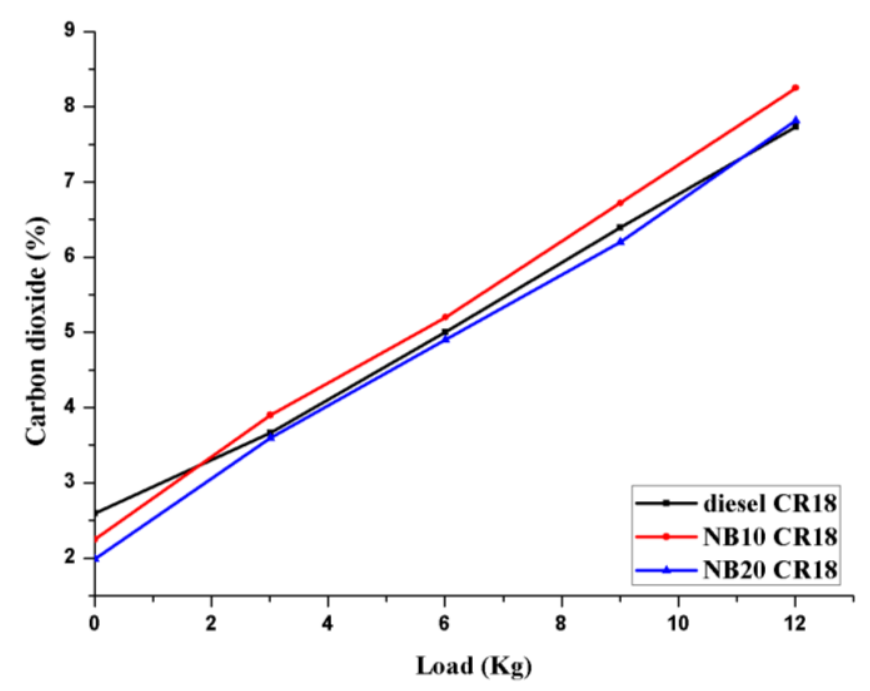

(b)

Figure 5. Variation of carbon dioxide emission with load at (a) CR16 and CR20 and; (b) CR18.

\section{Analysis of unburnt hydrocarbons}

The variation of $\mathrm{HC}$ emissions with respect to load is shown in Figures 6(a) and 6(b). HC emissions were increased for both n-butanol blends compared to diesel, as shown in figures at all the compression ratios. The addition of n-butanol into diesel influenced the reduction of viscosity, which in turn influenced the atomization and spray formation of injected fuel. The lower viscosity of the injected fuel resulted in smaller droplet size. The addition of n-butanol also caused micro-explosions after the fuel was injected into the combustion chamber. The smaller droplet size and micro-explosions caused improvement in volatility, which in turn influenced over mixing of n-butanol blends into the air [19]. 
This is considered as one of the factors for increased $\mathrm{HC}$ emissions. Another factor for the increase of $\mathrm{HC}$ emissions for n-butanol blends was "lean outer flame zone" where the flame was unable to travel which was due to the high latent heat of evaporation of butanol blends led to poor mixing of fuel blend with air, and increased spray penetration causing unwanted fuel impingement on cylinder walls.

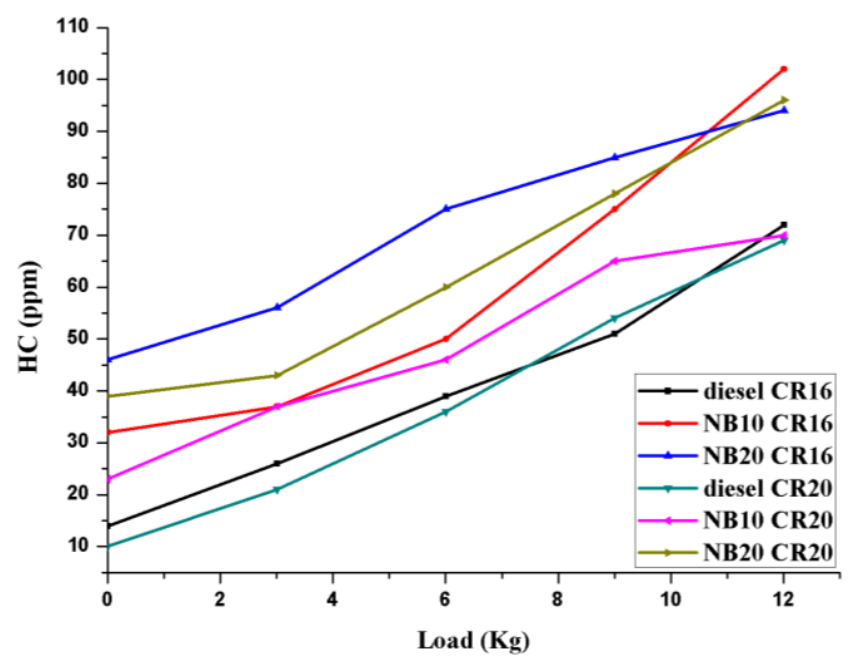

(a)

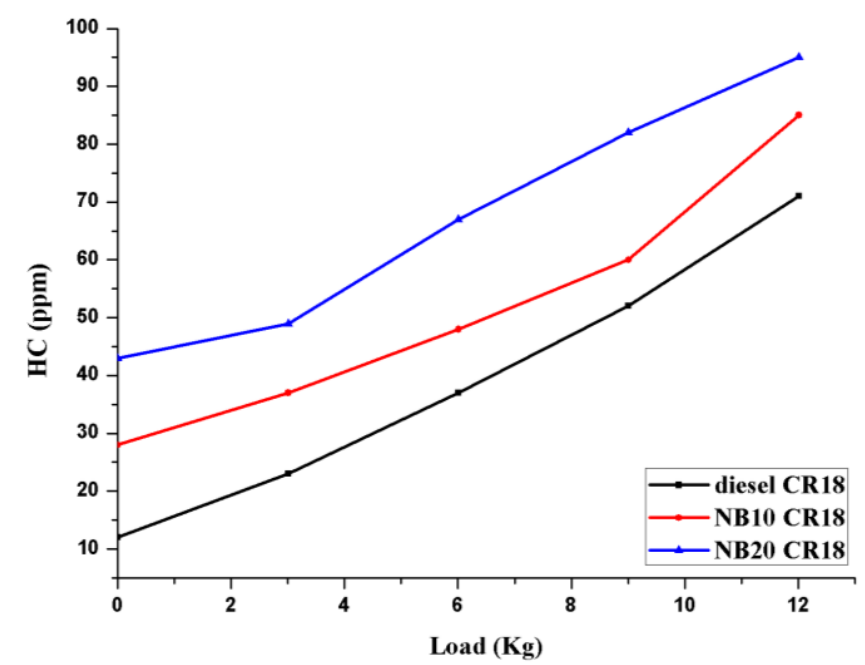

(b)

Figure 6. Variation of hydrocarbon emission with load at (a) CR16 and 20 and;

(b) CR18.

The HC emissions for diesel, NB10 and NB20 for full load conditions at CR16 were $72 \mathrm{ppm}, 102 \mathrm{ppm}$ and $94 \mathrm{ppm}$ and at CR20 they were observed as $69 \mathrm{ppm}, 70 \mathrm{ppm}$ and $96 \mathrm{ppm}$ respectively. With the increase of compression ratio, $\mathrm{HC}$ emissions for NB10 and diesel were decreased in trend, and there was no considerable variation for NB20.

\section{Analysis of nitrogen oxides}

NOx emissions are due to the separation of diatomic nitrogen atoms $\left(\mathrm{N}_{2}\right)$ into monoatomic nitrogen atoms $(\mathrm{N})$ at elevated temperatures, which are highly reactive with 
$\mathrm{O}_{2}$ and water vapours and form emissions like $\mathrm{NO}$ and $\mathrm{NO}_{2}$. The NOx emission strongly depends on in-cylinder temperatures and resident time of nitrogen at those temperatures and the oxygen availability in reaction regions of the combustion chamber, from Figure 7(a) and 7(b) NOx emissions were more for both n-butanol blends compared to diesel. Another factor also influencing is the presence of high $\mathrm{O}_{2}$ percentage in $\mathrm{n}$-butanol blends, show more effect than their high latent heat of vaporisation, which in turn led higher NOx emissions. It also has been observed that lower cetane number of n-butanol blends increased the ignition delay period, which in turn caused higher in-cylinder pressures and combustion temperatures. The more quantity of fuel accumulation and oxygen percentage is also considered as another cause for increased NOx emissions [10].

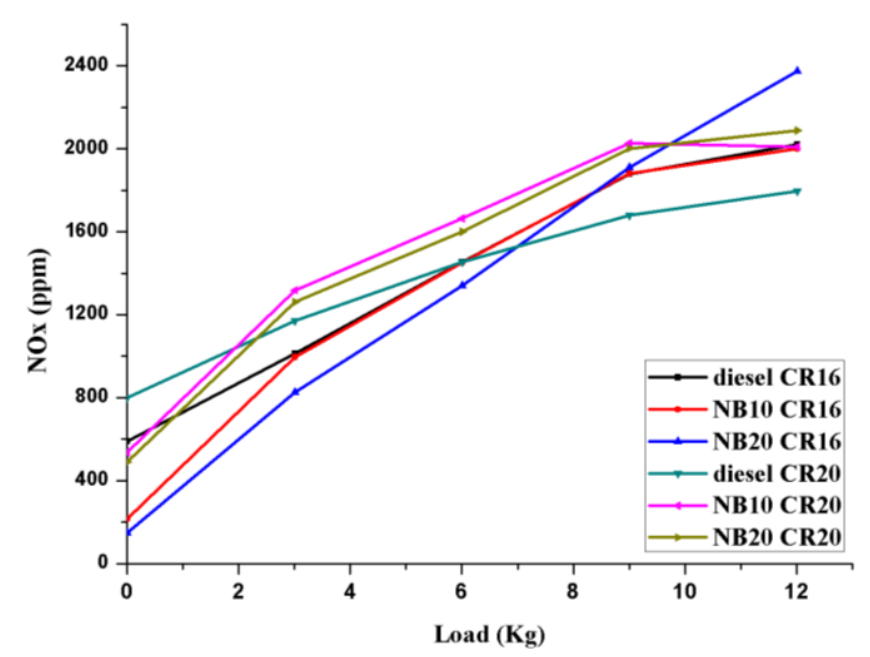

(a)

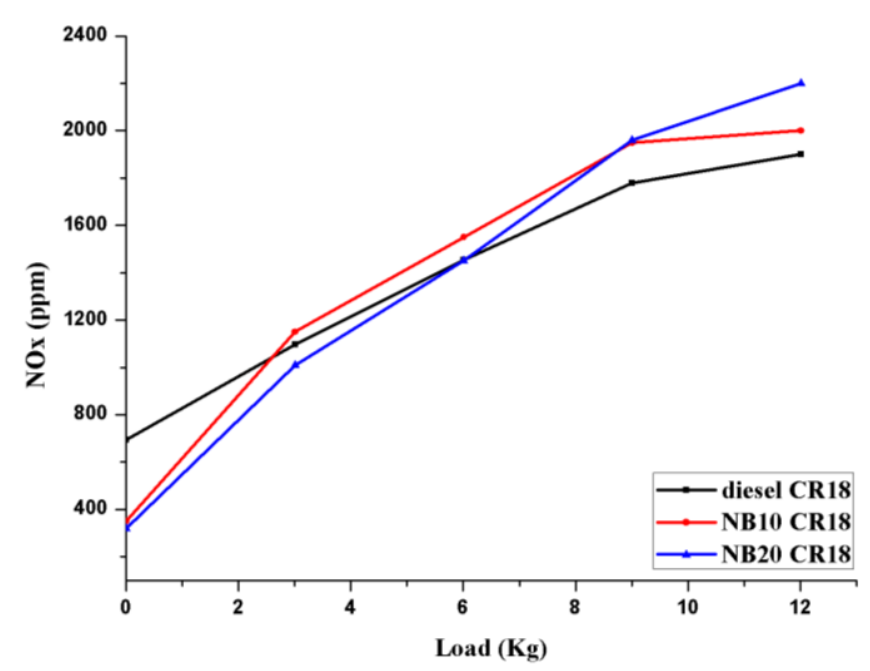

(b)

Figure 7. Variation of NOx emission with load at (a) CR16 and 20 and; (b) CR18.

The NOx emissions for full load conditions at CR16 were 1900 ppm, 2000 ppm and 2200 ppm and at CR20 they were 1796 ppm, 2008 ppm and 2088 ppm for diesel, NB10 and NB20 respectively as shown in Figure 7(a), intermediate results were obtained at a compression ratio of 18 as shown in Figure 7(b). 


\section{Analysis of smoke opacity}

The emission of smoke opacity is due to improper mixing of fuel particles with air. The emission of smoke compared to diesel is shown in Figures 8(a) and 8(b). Smoke opacity decreased for both blends compared to diesel at all the compression ratios. The volatility of n-butanol is higher compared to diesel fuel, even at low pressures. This causes nbutanol to break up easily and evaporate effectively compared to diesel [19].

Smoke opacity also depends on the H/C nature and combustion process. As the $\mathrm{H} / \mathrm{C}$ ratio is lower for diesel compared to n-butanol blends, which in turn caused higher smoke opacity for diesel compared to n-butanol blends. This emission also could be decreased by promoting premixed combustion before TDC. By using the n-butanol blends, the premixed combustion phenomenon also increased, which in turn led to increased burned fuel, which is shown in NHR figures in combustion analysis.

The emission of smoke opacity for diesel, NB10 and NB20 at CR16 was 53.9\%, $54 \%$ and $42 \%$. And at CR20 it was observed as $63.7 \%, 51.8 \%$ and $56.4 \%$. Intermediate results were obtained at CR18, as shown in Figure 8(b).

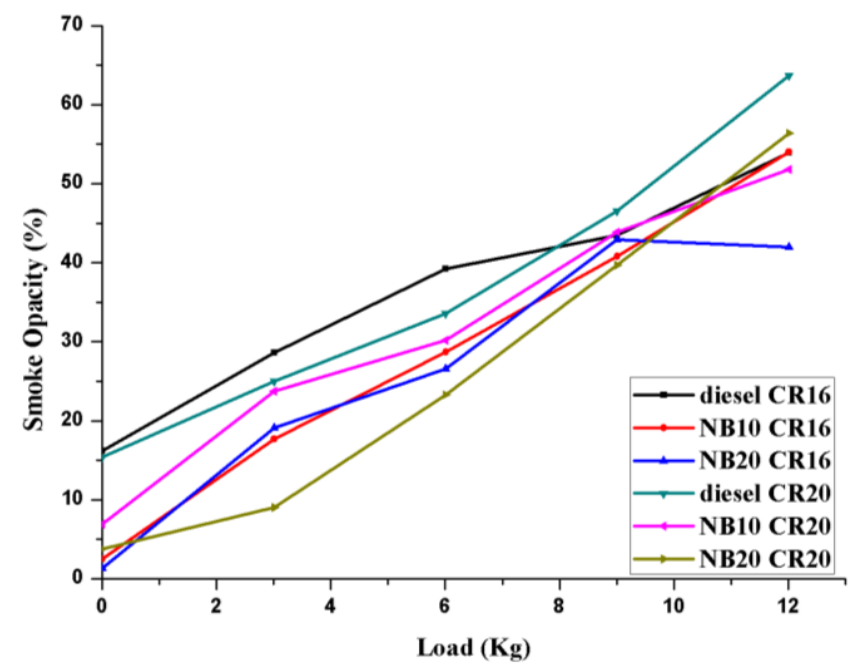

(a)

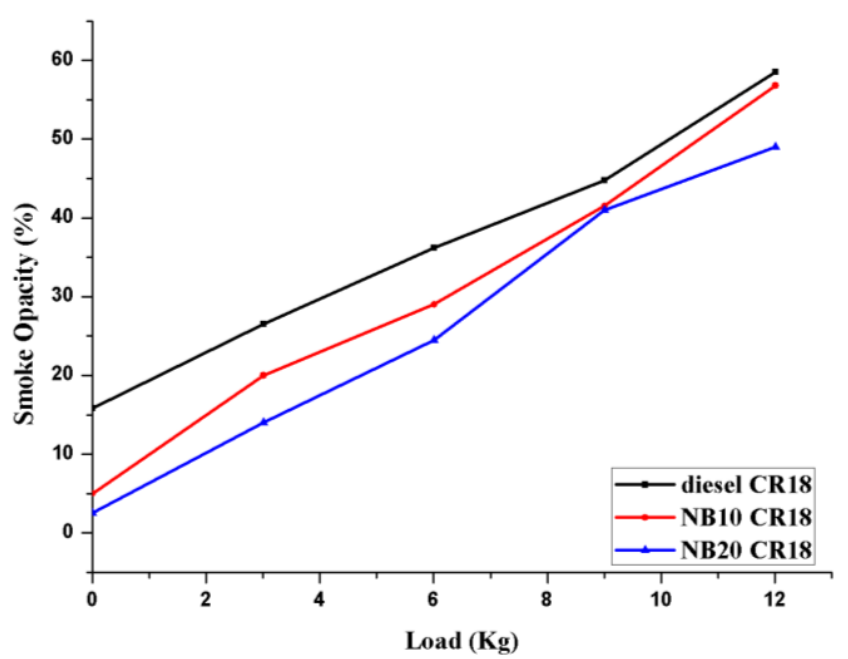

(b)

Figure 8. Variation of smoke opacity with load at (a) CR16 and 20 and; (b) CR18. 


\section{Combustion Analysis}

\section{Analysis of blends cylinder pressure}

The in-cylinder pressure is one of the useful parameters to analyse the combustion characteristics for the fuel which is chosen. In-cylinder pressure directly related to the performance parameters like power output and emission analysis. Variation of the incylinder pressure with respect to crank angle at full load for compression ratios 16 and 20 is shown in Figures 9(a) and 9(b). It has also been observed that peak cylinder pressures are just after TDC indicating the combustion not deviating from its regular phenomenon like using diesel at all compression ratios for both the blends. As shown in the figure, n-butanol blends resulted in higher peak pressures at all compression ratios compared to diesel combustion pressure rise because of its fast burning process and lowpressure vaporisation [20].

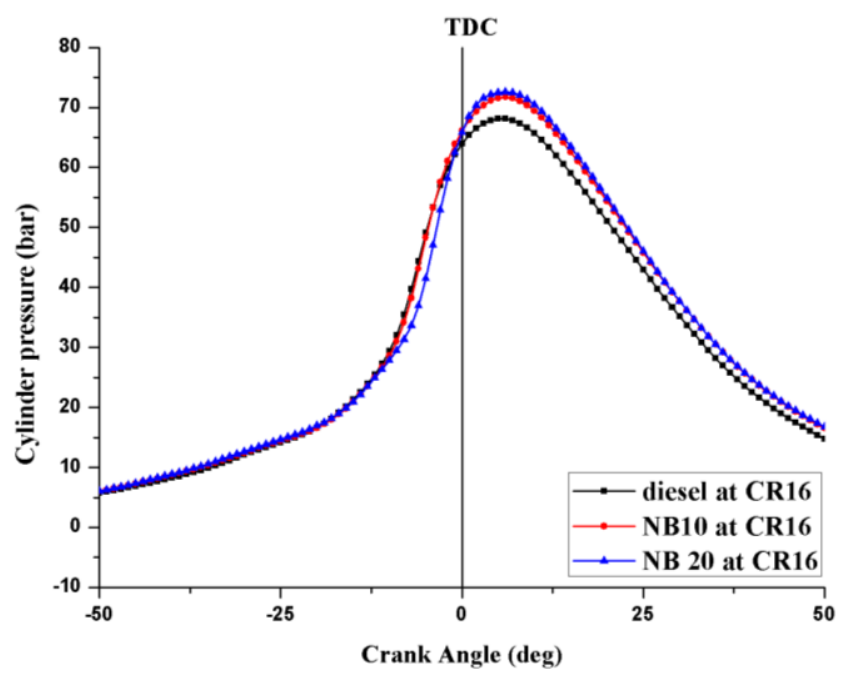

(a)

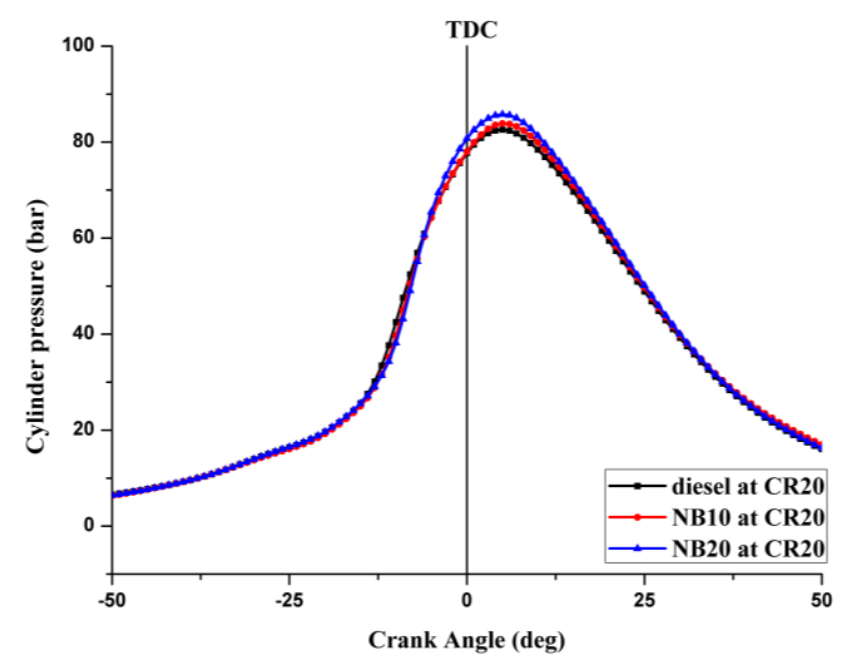

(b)

Figure 9. Variation of cylinder pressure with the crank angle at (a) CR16 and; (b) CR20. 
In the presented cases, the compression ratio shows a dominant influence on peak pressure rates. In Figure 9(b), as the compression ratio increases the peak pressure rates also raised. These maximum pressures were also increased because of the blend strength of n-butanol. Peak pressures were also due to oxygen percentage in n-butanol and its heating value near to diesel. Longer ignition delay because of lower cetane number of nbutanol blends caused the maximum quantity of fuel accumulation before premixed combustion. The high rate of pressure rise occurs when premixed combustion initiates because of the large amount of fuel burnt which was accumulated in the form of vapour during the ignition delay period [21].

The increased fuel supply with elevated loads, which in turn increased operating temperatures and evaporation rates is also considered as another factor for increased cylinder pressures. The peak pressure obtained at compression ratio 16 for diesel was 68 bar and for NB10, NB20 it was 71.7 bar and 72.6 bar respectively. The peak pressures increased by $5.16 \%$ and $6.33 \%$ at CR16, and at CR20 peak pressures were improved by $1.56 \%$ and $3.75 \%$ for both the blends NB10 and NB20 respectively compared to diesel. Intermediate pressure rises were obtained at CR18.

\section{Analysis of blends heat release rate}

The fuel properties, operating parameters like injection pressure and compression ratio influences the net heat release rates. NHR analysis is the better way to do an in-depth analysis of the combustion phenomenon. Conjoining the NHR analysis, in-cylinder pressure characteristics of the fuels can be studied in a better way. The variation of NHR with respect to crank angle at full load conditions for compression ratios 16 and 20 is shown in Figures 10(a) and 10(b).

The elevated NHRs were observed for both the blends at all compression ratios at peak load conditions compared to diesel, as an oxygenated fuel n-butanol has comparable calorific value and cetane number with diesel. Improved evaporation rate and combustion temperatures even at lower pressures were also considered as another factor for improved NHR for n-butanol blends. Negative NHR was observed for all the fuels near to $22^{\circ}$ BTDC, because of heat absorption while evaporation of fuel was going on at ignition delay period [22].

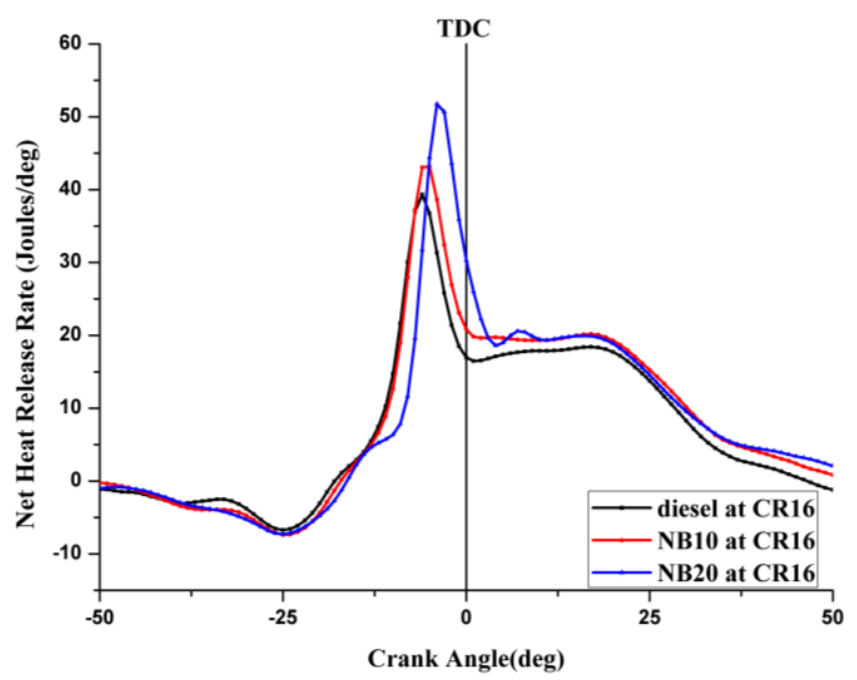

(a) 


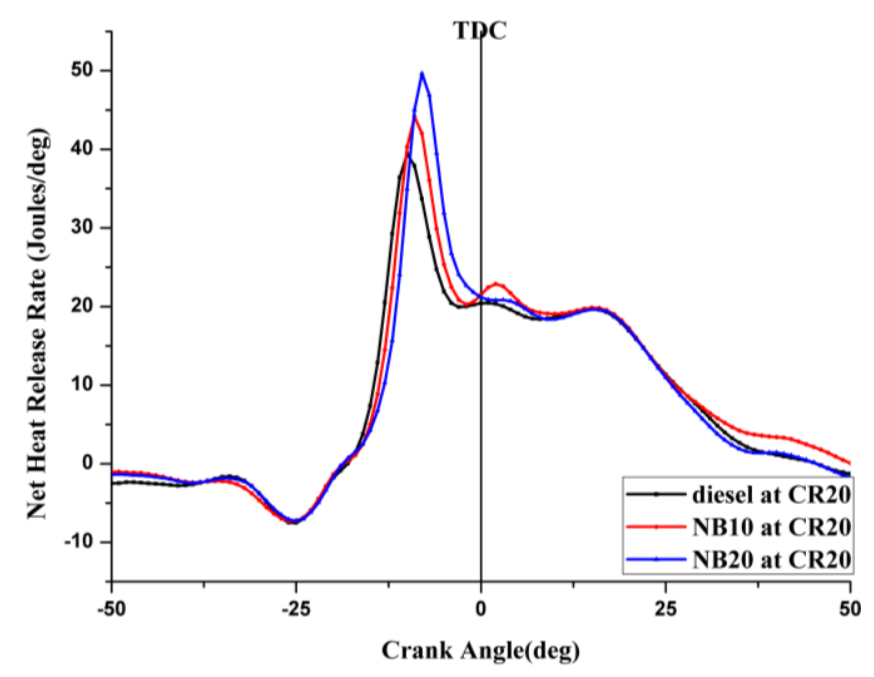

(b)

Figure 10. Variation of NHR with the crank angle at (a) CR16 and; (b) CR20.

It also has been observed that the ignition delay period is slightly improved for both the blends compared to diesel, and it is improved further as the blend strength increased further from 10 to $20 \%$. Lower cetane number for n-butanol compared to diesel is considered as one factor for increased ignition delay. But as the compression ratio increased the ignition delay period reduced because of increased operating temperatures. The maximum Net heat release rate was observed at CR16 for diesel at $7^{\circ} \mathrm{BTDC}$ as 39.33 $\mathrm{J} /{ }^{\circ} \mathrm{CA}$, for NB10 it was observed at $5^{\circ} \mathrm{BTDC}$ as $43.2 \mathrm{~J} /{ }^{\circ} \mathrm{CA}$, and for NB20 it was 51.77 $\mathrm{J} /{ }^{\circ} \mathrm{CA}$ at $4^{\circ} \mathrm{BTDC}$. And at CR20 the maximum NHR observed at $8^{\circ} \mathrm{BTDC}$ as $49.66 \mathrm{~J} /{ }^{\circ}$ CA for NB20, means with an increase in compression ratio ignition delay period slightly decreased and maximum NHR obtained some time earlier to TDC. NHR was improved with an increase in blend strength also because of maximum evaporation rates and oxygen percentages of n-butanol blends.

\section{Analysis of blends mass fraction of the fuel burned}

It is used for estimating time lag between flame initiation and rapid combustion, and it is also called as a fraction of amount of injected fuel burned to the total mass of fuel injected per cycle for the combustion process. It is the process of normalising the cumulative heat Release at each crank angle to the total heat release rate [23]. Slight combustion delay occurred at the early part of premixed combustion for both the blends compared to diesel but this delay was reduced with the increase of compression ratio from 16 to 18 and 20 respectively as shown in Figure 11(a) and 11(b). As the compression ratio increased operating temperatures were also increased, this, in turn, led to increased volatility and flame speed of n-butanol blends.

The mass fraction of fuel burnt completed $100 \%$ like a diesel at the same crank angle for both the blends. The MFB at TDC at CR16 for diesel, NB10 and NB20 was $53.17 \%, 52.15 \%$ and $52.62 \%$ and at CR20 it was $58.98 \%, 58.49 \%$ and $60.77 \%$ respectively. It is observed that MFB was slightly more for NB20 with increased compression ratio indicating better quality of combustion, as shown in Figure 11(b). 


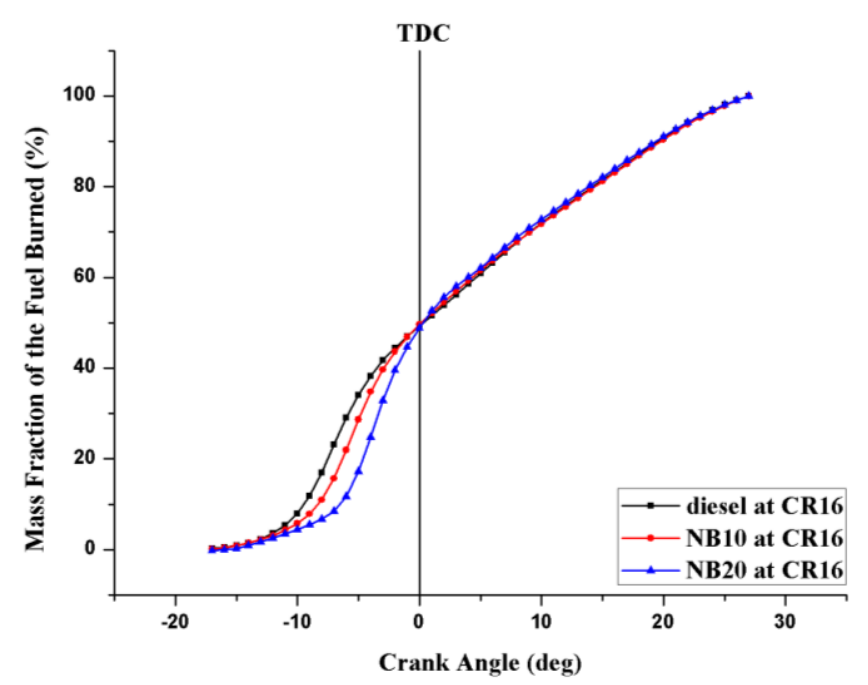

(a)

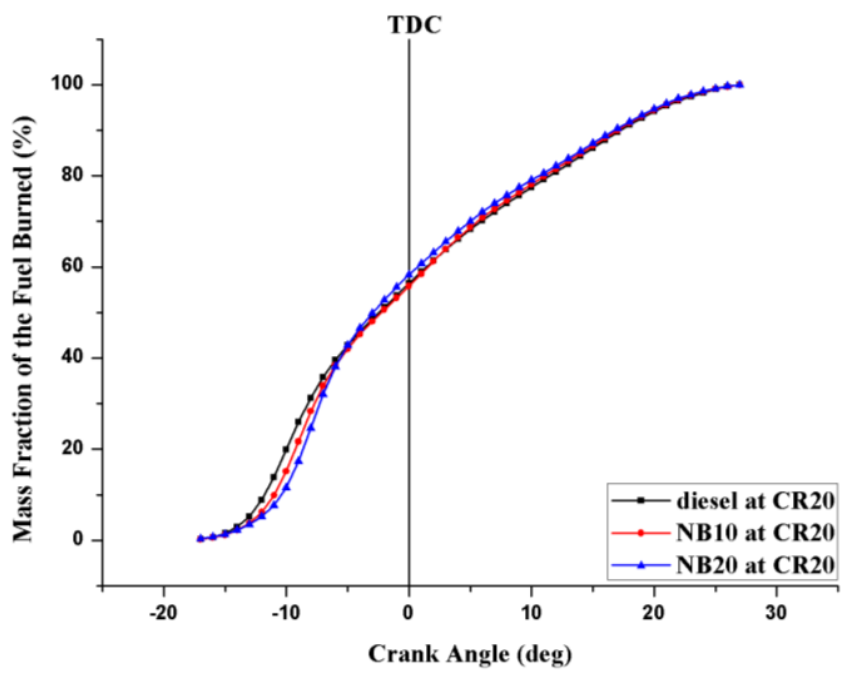

(b)

Figure 11. Variation of MFB with the crank angle at (a) CR16 and; (b) CR20.

\section{Analysis of blends cumulative heat release}

Cumulative or gross heat release at peak loads compared to diesel for both blends is shown in Figure 12. It is the total heat released by the chemical reaction or combustion of the fuel. The CHR provides information regarding the progress of combustion and heat energy released by the particular chemical nature of the fuel [16]. The figure shows the maximum CHR for both the blends compared to diesel. This trend was because of rapid ignition or better ignition property of n-butanol blends compared to diesel. CHR continuously increased with increase in the volume fraction of n-butanol blends because of higher energy content, and oxygen percentages of n-butanol blends. Later with an increase in compression ratio, the CHR for diesel was also comparable with n-butanol blends because of higher operating temperatures with an increase in pressures. The variation of CHR at all three compression ratios is shown in Figure 12(a) and 12(b).

The maximum CHR at CR16 observed as $0.9 \mathrm{~kJ} /{ }^{\circ} \mathrm{CA}, 1.02 \mathrm{~kJ} /{ }^{\circ} \mathrm{CA}$ and 1.04 $\mathrm{kJ} /{ }^{\circ} \mathrm{CA}$, and with CR20 they were observed as $1.01 \mathrm{~kJ} /{ }^{\circ} \mathrm{CA}, 1.07 \mathrm{~kJ} /{ }^{\circ} \mathrm{CA}$ and $1.03 \mathrm{~kJ} /{ }^{\circ} \mathrm{CA}$ 
for diesel, NB10 and NB20 respectively at full load conditions. Intermediate results were obtained at CR18.

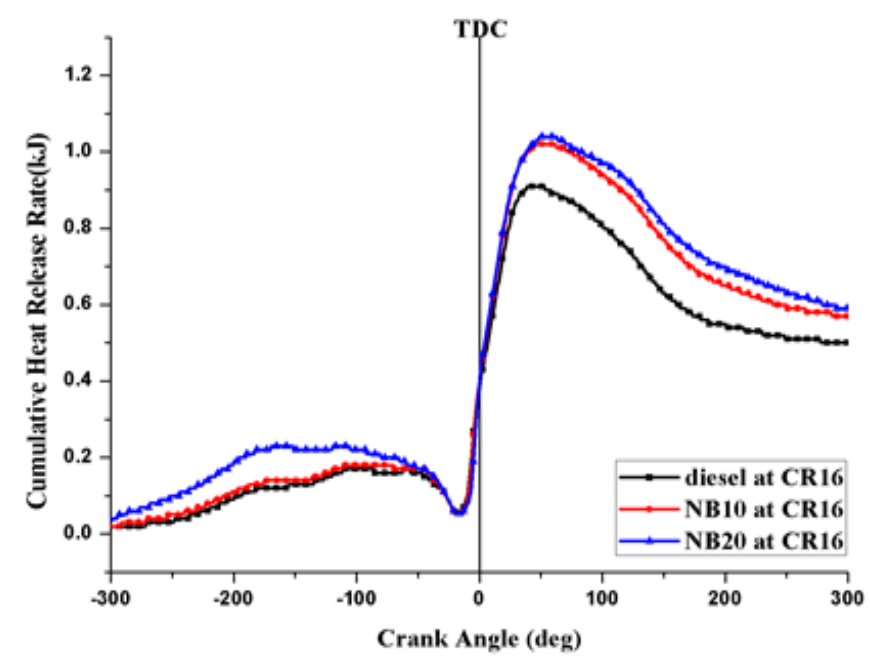

(a)

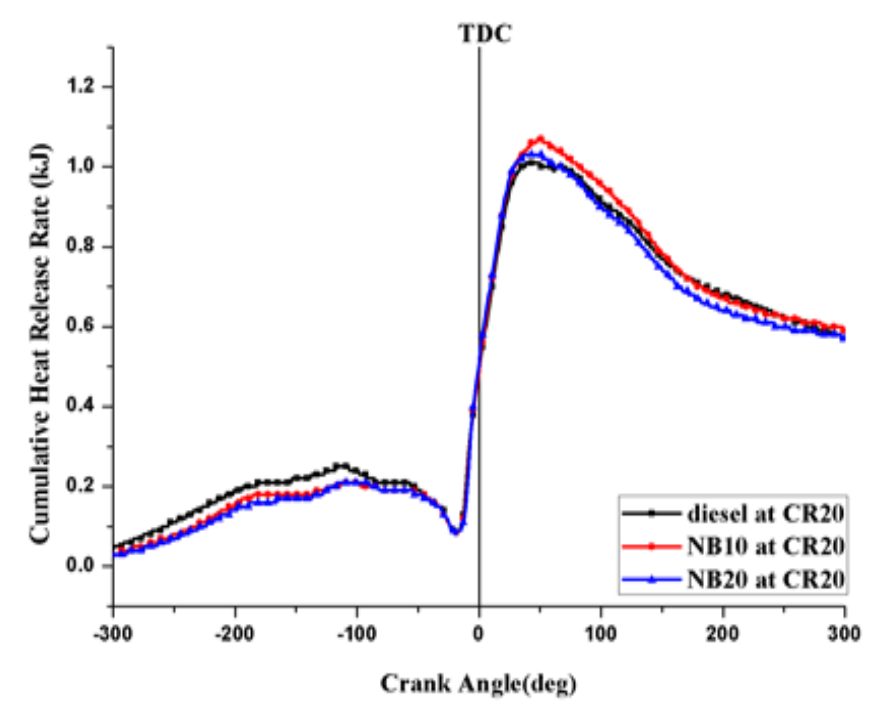

(b)

Figure 12. Variation of CHR with the crank angle at (a) CR16 and; (b) CR20.

\section{CONCLUSION}

The experimental work using n-butanol blends at compression ratio of 16,18 and 20 has drawn the following conclusions in comparison to diesel.

i. If the n-butanol blend percentage increases further beyond NB20, the cetane value of the blend decreases. Furthermore, this leads to an increase in the ignition delay period. Another disadvantage using higher n-butanol blend strength is that it can improve oxygen percentages at reaction regions of the combustion chamber, which can further increase the NOx emission. This reason restricted the use of higher blend strengths beyond NB20.

ii. The peak cylinder pressures were just after TDC, indicating that the combustion was not deviating from its regular phenomenon like using diesel at all 
compression ratios for both the blends. The pressure rising trend was followed like a diesel with variation in crank angle, and no unusual behaviour was observed.

iii. The n-butanol blends resulted in higher peak pressures at all compression ratios compared to diesel combustion pressure rise because of its fast burning process and low-pressure vaporisation.

iv. Maximum NHR was observed for both the blends compared to a diesel with increased ignition delay as there was a decreased cetane number by adding nbutanol blends. All the blends showed an improved NHRs compared to diesel at all compression ratios.

v. The rate of combustion was faster with increased mass fraction burned for all blends as the compression ratio increased.

vi. Increased BSFCs with a slight reduction in BTEs were observed for both blends compared to diesel.

vii. The emissions like $\mathrm{NOx}, \mathrm{CO}_{2}$ and $\mathrm{HC}$ for both the blends were slightly increased compared to diesel at all compression ratios.

viii. This analysis also concluding to concern over suitable injection pressure, which was maintained constant, even compression ratios were increased. There is a need to vary injection pressures too in its future scope of work.

From all above it has been proved that the n-butanol could be added to diesel in small proportions to save conventional fuel usage for diesel engines.

\section{REFERENCES}

[1] Perumal V, Ilangkumaran M. Water emulsified hybrid pongamia biodiesel as a modified fuel for the experimental analysis of performance, combustion and emission characteristics of a direct injection diesel engine. Renewable Energy 2018; 121: 623-631.

[2] Han X, Yang Z, Wang M, et al. Clean combustion of $n$-butanol as a next generation biofuel for diesel engines. Applied Energy 2017; 198: 347-359.

[3] Rezaei J, Shahbakhti M, Bahri B, et al. Performance prediction of HCCI engines with oxygenated fuels using artificial neural networks. Applied Energy 2015; 138: 460-473.

[4] Senthur Prabu S, Asokan MA, Prathiba S, et al. Effect of additives on performance, combustion and emission behavior of preheated palm oil/diesel blends in DI diesel engine. Renewable Energy 2018; 122: 196-205.

[5] Atmanli A, Ileri E, Yüksel B. Experimental investigation of engine performance and exhaust emissions of a diesel engine fueled with diesel-n-butanol-vegetable oil blends. Energy Conversion and Management 2014; 81: 312-321.

[6] Nair A. Characterization of n-butanol diesel blends on a small size variable compression ratio diesel engine: Modelling and experimental investigation. Energy Conversion and Management 2015; 106: 748-758.

[7] Nayyar A, Sharma D, Soni SL, et al. Characterization of n-butanol diesel blends on a small size variable compression ratio diesel engine: Modeling and experimental investigation. Energy Conversion and Management 2017; 150: 242258.

[8] Wakale AB, Banerjee S, Banerjee R. Experimental and chemical kinetic study of the impact of n-butanol blending on the gross engine performance of a CRDI engine. Energy Conversion and Management 2018; 178: 400-414. 
[9] Huang H, Liu Q, Teng W, et al. Improvement of combustion performance and emissions in diesel engines by fueling $n$-butanol/diesel/PODE3-4 mixtures. Applied Energy 2018; 227: 38-48.

[10] Choi B, Jiang X, Kim YK, et al. Effect of diesel fuel blend with n-butanol on the emission of a turbocharged common rail direct injection diesel engine. Applied Energy 2015; 146: 20-28.

[11] Şahin Z, Aksu ON. Experimental investigation of the effects of using low ratio nbutanol/diesel fuel blends on engine performance and exhaust emissions in a turbocharged DI diesel engine. Renewable Energy 2015; 77: 279-290.

[12] Fathi M, Saray RK, Checkel MD. The influence of Exhaust Gas Recirculation (EGR) on combustion and emissions of n-heptane/natural gas fueled Homogeneous Charge Compression Ignition (HCCI) engines. Applied Energy 2011; 88: 4719-4724.

[13] Mohebbi M, Reyhanian M, Hosseini V, et al. Performance and emissions of a reactivity controlled light-duty diesel engine fueled with n-butanol-diesel and gasoline. Applied Thermal Engineering 2018; 134: 214-228.

[14] Tamilselvan P, Nagarajan G. Combustion and emission characteristics of a diesel engine fuelled with biodiesel having varying palmitic acid, stearic acid and oleic acid in their fuel composition. 2014; 8: 353-368.

[15] Taylor P, Savariraj S, Ganapathy T, et al. Engine fuelled with biodiesel having varying saturated fatty acid composition. International Journal of Green Energy 2012; 10:9, 952-965. 37-41.

[16] Tamilselvan P, Nagarajan G, Sasikumar M. Performance and emission characteristics of a diesel engine using blends of biodiesel by varying saturated fatty acid compositions. 2016; 9: 508-513.

[17] Varatha. Effect of n-butanol and diethyl ether as oxygenated additives on combustion-emission-performance characteristics of a multiple cylinder diesel engine fuelled with diesel-jatropha biodiesel blend. Energy Conversion and Management 2015; 94: 84-94.

[18] Subbarayan MR, Senthil JS. A study of performance and emissions of Direct Injection diesel engine fuelled with cotton seed oil methyl ester and pumpkin seed oil methyl ester and its blends with diesel using Exhaust Gas Recirculation. 7269. Epub ahead of print 2015.

[19] Şahin Z, Durgun O, Aksu ON. Experimental investigation of n-Butanol/diesel fuel blends and n-butanol fumigation: Evaluation of engine performance, exhaust emissions, and heat release. Green Energy and Technology 2018; 103: 47-65.

[20] Varatha. Combustion characteristics of a gasoline engine with independent intake port injection and direct injection systems for n-butanol and gasoline. Energy Conversion and Management 2016; 124: 556-565.

[21] Varatha. A comparative analysis on combustion and emissions of some next generation higher-alcohol/diesel blends in a direct-injection diesel engine. Energy Conversion and Management 2016; 119: 246-256.

[22] EL-Seesy AI, Hassan H, Ookawara S. Performance, combustion, and emission characteristics of a diesel engine fueled with Jatropha methyl ester and graphene oxide additives. Energy Conversion and Management 2018; 166: 674-686.

[23] Prakash T, Geo VE, Martin LJ, et al. Effect of ternary blends of bio-ethanol, diesel and castor oil on performance, emission and combustion in a CI engine. Renewable Energy 2018; 122: 301-309. 